\title{
Editorial
}

\section{A New High-Standard Journal Contributing to the Development of Sustainable Construction Materials}

\author{
Martin Cyr (1)
}

check for updates

Citation: Cyr, M. A New High-Standard Journal Contributing to the Development of Sustainable Construction Materials. Constr. Mater. 2021, 1, 80-81. https://doi.org/ 10.3390/constrmater1010005

Received: 6 May 2021

Accepted: 7 May 2021

Published: 18 May 2021

Publisher's Note: MDPI stays neutral with regard to jurisdictional claims in published maps and institutional affiliations.

Copyright: (c) 2021 by the author Licensee MDPI, Basel, Switzerland. This article is an open access article distributed under the terms and conditions of the Creative Commons Attribution (CC BY) license (https:// creativecommons.org/licenses/by/ $4.0 /)$.
Laboratory of Materials and Durability of Constructions, INSA/UPS Civil Engineering, University Toulouse III, 31077 Toulouse, France; martin.cyr@univ-tlse3.fr

Materials for construction have evolved over the years, but they still need improvement in order to be environmentally and technically better.

On the one hand, decreasing the environmental impact of materials/structures is an objective put forward by almost all the actors involved in the domain of construction. Although most construction materials intrinsically have low embodied energy, their use in large volumes in worldwide construction leads to high overall $\mathrm{CO}_{2}$ emissions. For instance, Portland cement is the main constituent responsible for the environmental impacts caused by the life cycle of concrete, as it generates on average more than $800 \mathrm{~kg} \mathrm{CO}_{2} / \mathrm{t}$ of clinker [1]. As business-as-usual practices will probably lead to a significant increase in $\mathrm{CO}_{2}$ emissions, efforts need to be made to improve the environmental impact of construction materials.

On the other hand, the future development of construction materials cannot be made without considering their technical (and economical) properties. The understanding of the mechanisms responsible for the modification of materials leaves a huge field to be filled by the researchers.

Construction Materials (ISSN 2673-7108) is a new, international, open access, peerreviewed journal that will publish research findings and developments in the field of construction materials. The journal will focus on the preparation and characterization of all kinds of construction materials, the relationship between properties and applications, as well as environmental impacts of construction materials. It will publish reviews, regular research papers (articles), short communications, among others.

The topics will cover several types of materials: cements, concretes, mortars, geopolymer and alkali-activated materials, recycled materials, additives, bituminous materials, steels, etc. The studies could be related to characterization and structure, materials properties, modeling, applications, multi-functions, durability, test methods, life cycle assessment, environmental impacts, and eco-efficiency.

The Editorial Board and I, as Editor-in-Chief, welcome researchers worldwide to contribute to Construction Materials and make this journal a high-standard medium with important influence in this key and stimulating field.

Conflicts of Interest: The author declares no conflict of interest.

\section{Reference}

1. World Business Council for Sustainable Development. Cement Industry Energy and $\mathrm{CO}_{2}$ Performance: Getting the Numbers Right (GNR). 2016. Available online: https: //www.wbcsd.org/Sector-Projects/Cement-Sustainability-Initiative/Resources/CementIndustry-Energy-and-CO2-Performance (accessed on 12 May 2021). 


\section{Short Biography of Author}

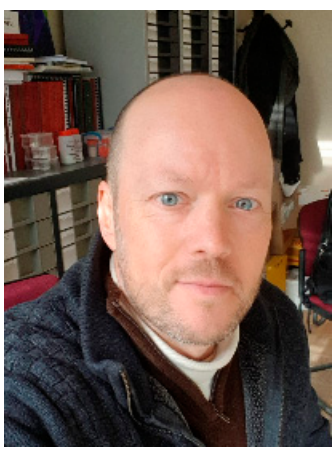

Martin Cyr is a Professor at Toulouse University (France) and Associate Professor at Sherbrooke University (Canada). He is deputy director of the Laboratory for Materials and Durability of Construction (Toulouse, France). His research interests include low-carbon concretes, mineral admixtures, alkali-activated materials, and durability of concrete. He is a member of several RILEM technical committees, and a convenor of the Technical Group TG4.8 «Low-carbon concrete structures» (FIB-International Federation for Structural Concrete) and of the Working Group CEN/TC 104/WG 15-Ground granulated blast furnace slag (European Committee for Standardization-CEN). He manages several projects with more than 20 researchers ( $\mathrm{PhD}$, post-doc, engineers), in partnership with several industrial groups. 